(C)British Editorial Society of Bone and Joint Surgery doi:10.1302/0301-620X.89B12.20455 \$2.00 J Bone Joint Surg [Br] 2007;89-B:1676.

\section{Surgery of the foot and ankle}

Edited by M. J. Coughlin, R. A. Mann and C. L. Saltzman

Pp. 2400. Philadelphia: Elsevier, 2007. ISBN: 13-978-0323-03305-3. £299.00.

First published in 1959, this authorative book has now reached its eighth edition and a third editor has been included, Professor Charles Saltzman of The University of Utah School of Medicine. A combination of electronic text and hard copy has brought the work into the 21 st century. Its value has been enhanced by the inclusion of video clips of key surgical procedures, made available on the compact discs included with each volume. They display each operation according to the author's preferred technique - an optimal method for learning. Furthermore, updates are promised to be available on the 'web' every three months, for several sections of the book. There is a small user handbook attached which is necessary to guide the reader as to how best to use the additional electronic information.

The text has been beautifully produced and many of the numerous illustrations are in colour, a welcome but uncommon feature nowadays. Books have lives of their own and there is a high early mortality. Now, nearly 50 years old, this two volume book has joined the ranks of classic texts, so that no self-respecting foot and ankle surgeon can afford to be without it. One is unlikely to come across problems which cannot be found described in this book in some detail. The editors, all practising surgeons who have a consistently high publication rate of clinical papers, are to be congratulated on finding time to produce this new book and to keep it on course for a ninth edition. Inevitably, as it now weighs $7 \mathrm{~kg}$, it is not suitable for bedside reading.

L. Klenerman

\section{Practical procedures in orthopaedic trauma surgery: a trainee's companion}

Edited by P. V. Giannoudis and H.-C. Pape

Pp. 319. Cambridge: Cambridge University Press, 2006. ISBN: 0-5216-7859-5. $£ 45.00$.

This is a curious book. Only on the internal flyleaf is the subtitle "A Trainee's Companion", added, which is important when a work is to be assessed. The foreword describes the book as 'highly illustrated'. which is an understatement. Operative colour photography is taken beyond its limit, demonstrating the limitation of this mode of illustration; and the several photographs of huge trays of instruments on sterile theatre tables simply show how expensive it has all become. By contrast, the radiographs give much more information about the conditions and the techniques.

The book's message concerns operative fixation of fractures. Ideally, it requires a companion volume on the 'why and whether', because several of the cases illustrated would seem to be eminently treatable without surgery. But to cover the whole of fracture management is beyond the scope of any book. This one is aimed at the idle hours in the night when a young resident is already committed to an operation and he wants reassurance as to 'how'. We still have the ageold conflict between what is possible and what is wise.

The text, in punctuate bullet form, is curiously difficult to read because of the shortage of verbs imposed by the tabloid format. This is exaggerated by the difficulty in deciphering the important points from the dash and blur of brilliant shades of red. One point is clear; the authors have an immense experience of internal fixation and an unlimited supply of hardware.

There is a place for such a book as this aims to be, but there needs to be more critical planning of the techniques of illustrating the practical points. At the end of the day, there is no substitute for the teacher's guiding hands in performance.

M. Laurence

\section{Surgical techniques in sports medicine} Edited by N. S. El Attrache, C. D. Harner, R. Mirzayan and J. K. Sekiya

Pp. 694. Philadelphia: Lipincott, Williams and Wlkins, 2007. ISBN: 13-978-0-78175427-9. \$199.00.

This is a comprehensive multi-author text edited by four orthopaedic surgeons. The contributors include medical students, residents, instructors and professors largely from North America. Most are orthopaedic surgeons but with some input from clinical researchers. In the preface, the authors state that the emphasis of the book is on surgical technique and this is certainly reflected, but with some useful, albeit at times limited, information on clinical diagnosis, evaluation and imaging. It is certainly a comprehensive and contemporary text with each chapter structured in a reader-friendly, systematic fashion.

As a Sport and Exercise Medicine physician, I typically work as part of a multidisciplinary team. Success of such working is an understanding of the strengths and weaknesses, thought patterns and capabilities of each team member. Thus, while this book will have particular appeal to orthopaedic surgeons I believe it is also of considerable value to others working within multidisciplinary sports medicine teams. The authors recognise the increasing importance of sports injuries in our children and adolescents in addition to those of advancing years; this is reflected in some of the core content of this book. For the most part, the images and illustrations are well produced, pertinent and useful; they certainly add to the visual appeal of the text.

I particularly enjoyed the sections of each chapter addressing indications and contraindications to surgery, as clearly the decision to operate or not is more important than the procedure itself. My only significant reservation resides in the area of rehabilitation and return to play, which is frequently sparse on detail and therefore limits its usefulness. I would recommend this text to all those working in the fields of Sport and Exercise Medicine and Orthopaedic Surgery. Readers should understand and appreciate that individual chapters often reflect personal experience from some of the world's foremost surgeons in this attractive area of medicine.

Professor M. E. Batt 